\title{
Clinical, laboratory and chest computed tomography aspects of hospitalized patients with COVID-19 in northern Iran
}

\author{
ali sharifpour ${ }^{1}$, sepideh Safanavaei ${ }^{1}$, Rabeeh Tabaripour ${ }^{2}$, fatemeh Taghizadeh $^{3}$, maryam \\ nakhaei $^{1}$, atikeh abadi ${ }^{1}$, Mahdi Fakhar ${ }^{2}$, Elham Sadat Banimostafavi ${ }^{1}$, Sayed Rasooli ${ }^{1}$, \\ Masoud aliyali ${ }^{1}$, Siavash abedi ${ }^{1}$, and Hossein Hossein Mehravaran ${ }^{1}$ \\ ${ }^{1}$ Mazandaran University of Medical Sciences Faculty of Medicine \\ ${ }^{2}$ Affiliation not available \\ ${ }^{3}$ Mazandaran University of Medical Sciences
}

November 30, 2020

\begin{abstract}
The clinical symptoms, blood laboratory data, O2 saturation and high resolution computed tomography (HRCT) findings are critical factors in diagnosis of COVID-19 infection. In this study, 105 hospitalized patients suspected of having COVID-19 were evaluated. Finally, the data of 83 confirmed cases by HRCT and RT-PCR were analyzed. $61.40 \%$ of the patients had a comorbidity disease. $89.20 \%$ had fever, $92.00 \%$ cough, $91.40 \%$ dyspnea. Abnormal CRP seen in $77.80 \%$ of the patients following by $66.70 \%$ lymphopenia, and $60.30 \%$ neutrophilia. Also, ALP (abnormal vs. normal) and score of HRCT assessment variables had a significant effect on the positiveness of HRCT findings. $87.95 \%$ had abnormal HRCT with $41 \%$ bilateral multilobar patchy ground glass opacity (GGO). Moreover, there was a statistically significant association between level of O2 saturation and HRCT results. Our findings showed that male patients with middle age and comorbidity disease were more susceptible to the COVID-19 infection. Additionally, clinical features, blood laboratory findings, O2 saturation and HRCT findings are critical factors in prognosis of COVID-19 infection.
\end{abstract}

\section{Introduction}

A current outbreak of pneumonia related to a novel coronavirus, termed severe acute respiratory syndrome coronavirus 2 (SARS-CoV-2), was reported in Wuhan, Hubei province, China in December 2019. The infection spread across other countries round the world (Zhu et al.). On January 30, 2020, the World Health Organization (WHO) stated the outbreak a Public Health Emergency of International Concern (Sohrabi et al., 2020).the symptoms of COVID-19 can be fever, dry cough, fatigue, shortness of breath, myalgia or even no symptoms (Diao et al., 2020, Wan et al., 2020, Shang et al., 2020, Huang et al., 2020, Zarghami et al., 2020).likewise, the studies revealed that older age, male gender, leukocytosis, and Blood laboratory findings, also, comorbidities such as high lactate dehydrogenase level, cardiac injury, hypertension, diabetes mellitus, hypothyroidism, coronary artery disease, smoking and hyperglycemia, were related to weak prognosis in COVID-19 patients (Zhang et al., 2020b, Li et al., 2020, Zarghami et al., 2019).Though, information concerning to clinical features of COVID-19 is still making it difficult for physicians to distinguish the causative agents without related laboratory analysis(Wu and McGoogan, 2020).Furthermore, reverse transcriptionpolymerase chain reaction (RT-), the gold standard for confirming diagnosis of COVID-19, has some restrictions, such as false negative results and limited sampling method and the rate of high false negative and unavailability of in the early stage of the outbreak restricted fast diagnosis of infection in patients(Fang et al., 2020). The high resolution computed tomography (HRCT) of the chest is progressively recognized as a strong indicator for early diagnosis, and can be the key to the evaluation of COVID-19 suspected patients because the changes in chest imaging sometimes maybe earlier than symptoms (He et al., 2020). HRCT is 
strongly recommended because it is very sensitive to detecting early disease, assessing the nature and extent of lesions (Yang et al., 2020a). Other investigators examined chest HRCTs in infected patients and found high rates of ground-glass opacities and consolidation, sometimes with a rounded morphology and peripheral lung distribution (Yang et al., 2020b, Pan et al., 2020, Chung et al., 2020).

Chest HRCT can identify the early phase lung infection(Wong et al., 2020, Kanne, 2020) and prompt larger public health surveillance and response systems (Ng et al., 2020). Currently, chest HRCT have been recommended as main evidence for confirmed clinical and laboratory diagnosis. Considering the previous studies, the purpose of the study is to make the early diagnosis, by describing the complete chest HRCT appearances, related laboratory analysis and clinical features of patients with COVID-19, who were hospitalized to the Imam Khomeini Hospital .

\section{Patients and Methods}

In this cross-sectional study, 105 patients suspected of having COVID-19 hospitalized in Imam Khomeini Hospital, during February 2020, were enrolled. Finally, the data of 83 confirmed cases by HRCT were analyzed. Demographic, clinical, HRCT features and laboratory data of the patients were extracted and analyzed. All HRCT images were reviewed blindly by 2 radiologists with working experiences to the clinical evidence. The severity of lung involvement was scored and classified into 3 categories (category 0: negative findings, category 1: less than $50 \%$ of the lung involvement, and category 2: up to $50 \%$ ) of the lung involvement. The current study was reviewed and approved by the Research Ethical Committee, XXXX (IR.XXXX.REC.1399.102) .

\section{Statistical analysis}

Quantitative variables as mean $\pm \mathrm{SD}$ and qualitative variables also were reported as frequency (\%). Chisquare and Fisher's exact tests were used for categorical variable comparison. In addition, to compare the median of quantitative variables in the two groups test was used. Then, first to determine the factors associated with the positiveness of HRCT result univariate logistic model was fitted, and those variables which had $\mathrm{P}<0.25$ were entered into the multiple model. Receiver operating characteristic (ROC) curves were constructed to test the ability of final model to predict the positiveness of HRCT result. All analysis was carried out in the version 20.0 and STATA Release version 12 . $\mathrm{P}<0.05$ was considered statistically significant.

\section{Results}

The mean age of the patients was $58.12 \pm 17.19$, and $46(55.40 \%)$ were males. There was not a statistically significant difference between the mean age of men and women $(\mathrm{p}>0.05) .33(89.20 \%)$ of the patients had fever, $46(92.00 \%)$ cough, and 53(91.40\%) had dyspnea. Furthermore, 6(7.23\%) had chill and 9(10.84\%) had myalgia (Table1). As well, analysis of the laboratory results showed that abnormal WBC was seen in $34(42.00 \%)$ of the patients, $54(66.70 \%)$ lymphopenia, $47(60.30 \%)$ neutrophilia, $56(77.80 \%)$ abnormal C-reactive protein (CRP), 18(22.00\%) abnormal platelet count test (), 40(66.70\%) abnormal lactate dehydrogenase (LDH), and $53(80.30 \%)$ had abnormal erythrocyte sedimentation rate (ESR). Moreover, the mean of O2 saturation was $93.89 \pm 4.77$, while, $37(44.60 \%)$ of them had insufficient O2 saturation. Furthermore, $32(54.20 \%)$ of cases had abnormal serum glutamic-oxaloacetic transaminase (SGOT), and 22(37.30\%) of cases had abnormal serum glutamic-pyruvic transaminase (SGPT), and 27(46.60\%) of them had abnormal Alkaline phosphatase (ALP) (Table2, Table3). Analysis of the HRCT results showed that $73(87.95 \%)$ had abnormal HRCT as follows: bilateral multilobar patchy ground glass opacities (GGO) 16(19.30\%), bilateral multilobar patchy ground glass opacities and bilateral alveolar consolidations 18 (21.70\%), Pleural effusion 7(8.40\%), bilateral alveolar consolidations $6(7.20 \%)$, unilateral /single lobar ground glass opacities $2(2.40 \%)$, unilateral/single lobar alveolar consolidation $2(2.40 \%)$, centrilobular nodules/tree in bud opacities $1(1.20 \%)$, other mixed disease13 $(15.60 \%)$ and any other findings $3(3.60 \%)$.

Moreover, 22(42.30\%) of women and $30(57.70 \%)$ of men tested positive for HRCT, which there was not a statistically significant association between the gender and HRCT result based on the results from the chisquare test $(\mathrm{p}>0.05)$. The mean age of the patients with negative and positive of HRCT was $58.13 \pm 18.26$ 
and 58.12 \pm 16.70 . Mann-Whitney test showed that there was not a statistically significant difference between the median of age in the two groups of HRCT result ( $\mathrm{p}>0.05)$. So that, $16(30.80 \%)$ patients under the $50 \%$ lung involvement and $36(69.20 \%)$ were over the $50 \%$ lung involvement (Table 1). Distribution dotplot of HRCT assessment of patients based on the HRCT result presented in figure 1. The mean W.B.C of the patients with negative and positive of HRCT was $16.90 \pm 34.70$ and $10.96 \pm 20.36$. Mann-Whitney test showed that there was a statistically significant difference between the median of W.B.C in the two groups of HRCT result $(\mathrm{p}<0.05)$ (Table 2). The mean O2 Saturation of the patients with negative and positive of HRCT tests was $95.03 \pm 4.49$ and $93.21 \pm 4.85$, respectively. Based on the results from Mann-Whitney, there was a statistically significant difference between the median of $\mathrm{O} 2$ saturation in the two groups of HRCT result $(\mathrm{p}<0.05)$. Out of a total of 52 positive cases, 23(44.20\%) positive cases at the level of normal oxygen and $29(55.80 \%)$ positive cases occurred at the level of abnormal oxygen. Based on the results from chisquare test, there was a statistically significant association between level of O2 saturation and HRCT results $(\mathrm{p}<0.05)$. The mean ALP of the patients with negative and positive of HRCT tests was $544.67 \pm 516.51$ and $313.84 \pm 227.36$, respectively. Results from the Mann-Whitney test showed that there was not a statistically significant difference between the median of ALP in the two groups of HRCT result ( $\mathrm{p}>0.05)$. In patients with normal ALP, 24(64.90\%) of the cases had a positive HRCT and in abnormal ALP patients, 13(35.10\%) of cases had a positive HRCT , which there was a statistically significant association between the level of ALP and HRCT result based on the results from the chi-square test $(\mathrm{p}<0.05)$ (Table 3). Frequency distribution of past medical history (PMH) among patients with suspected COVID-19 under study presented in Table which $51(61.40 \%)$ of patients had PMH.

Multiple logistic regression showed that ALP (abnormal vs. normal) and score of HRCT assessment variables had a significant effect on the positiveness of HRCT result $(\mathrm{P}<0.05)$. So that, by adjusting the effect of other variables, the odds of positiveness of HRCT result with abnormal ALP was 0.04 times as than those with normal ALP and this difference is statistically significant $(\mathrm{P}<0.05)$. Furthermore, by adjusting for the effects of other variables, for each unit increase in the score of HRCT assessment, the odds of positiveness of HRCT result of the patients were 5.17 times than those who did not have an increase $(\mathrm{P}<0.05)$. But other variables had no significant effect on the positiveness of HRCT result $(\mathrm{P}>0.05)$ (Table 5$)$. The area under the ROC curve of the model was 0.96, which indicate the good predictive power of the model (Figure 2).

\section{Discussion}

COVID-19 infection was seen typically in middle-aged, man gender and elderly patients, and patients with other diseases were more susceptible to disease. A greater number of men was found than that of women, which was similar to previous studies (Wang et al., 2020, Jiang et al., 2020). women have a humoral immune response and greater innate than men and are thus less susceptible to many parasitic, fungal, bacterial, and viral diseases, while being more prone to developing a malignancies or autoimmune disease (Schurz et al., 2019). While these sex differences in rates of mortality may be due to sex- specific life styles (smoking, alcohol etc.)(Wrapp, Zarghami et al., 2019). Cough, fever, and dyspnea were main symptoms. abnormal lymphocyte, neutrophil, , SGOT, and SGPT, increased CRP concentration and increased LDH concentration were the laboratory features of COVID-19 infection in present study. abnormal HRCT was seen in $88 \%$ of the patients as main indicator to evaluate the COVID-19 disease severity as other researchers(He et al., 2020, Zhang et al., 2020b).furthermore, WBC count, O2 saturation, and were associated to lung involvement significantly, statically.

\section{Other studies in clinical and laboratory findings}

a metanalyses showed that the main clinical manifestations of COVID-19 were fever, cough, and dyspnea (Jiang et al., 2020). in a study with 208 patients, median age was 50.5 years, $51.4 \%$ of them were men and $48.6 \%$ were women. $7.7 \%$ of the patients had pulmonary diseases, $19.7 \%$ hypertension, and $6.3 \%$ diabetes. In our study, $26.5 \%$ of the patients had diabetes, hypertension and Asthma. Among all symptoms, $70.2 \%$ and $55.3 \%$ were belonged to fever and cough respectively. In compatible, $20.2 \%$ cases had decreased white blood cell count, and $29.3 \%$ cases had declined lymphocyte count. $74 \%$ of them had elevated CRP, and $11.1 \%$ had elevated LDH in the present study (Zhang et al., 2020b). In a retrospective cohort study, The mean age of 
the patients were 59.5 years and $67 \%$ patients were male (Shi et al., 2020).In a study, of 138 hospitalized patients, the median age was 56 years and $54.3 \%$ were men. Common symptoms were included fever $98.6 \%$, and dry cough $59.4 \%$. Lymphopenia occurred in $70.3 \%$ patients. HRCT showed bilateral patchy shadows or ground glass opacity in the lungs of all patients (Wang et al., 2020). In a Meta analysis study, including a total of 50404 patients with 2019-nCoV infection, the incidence of fever was $90.9 \%$, and cough was $70.8 \%$, moreover the incidence of abnormal chest CT was $95.6 \%$ (Sun et al., 2020), abnormal HRCT in our study was $88 \%$. In a study in Beijing of 262 patients, the median age of patients was 47.5 and $48.5 \%$ of them were men. The most common symptoms at the onset of illness were fever (82.1\%), cough (45.8\%), dyspnea (6.9\%) (Tian et al., 2020) that compatible with our study. In the other study(Zhang et al., 2020a) of 140 hospitalized COVID-19 cases, a 1:1 ratio of men and women COVID-19 patients was found(50.7\%), with a median age of 57.0 . Fever $(91.7 \%)$, cough $(75.0 \%)$ were the most common clinical manifestations, whereas hypertension $(30.0 \%)$ and diabetes mellitus (12.1\%) were the most common comorbidities (Zhang et al., 2020a). Bilateral patchy opacity or ground glass $(89.6 \%)$ was the most common radiological finding. Lymphopenia $(75.4 \%)$ and eosinopenia $(52.9 \%)$ were seen in most cases. Eosinopenia with lymphopenia may be an indicator for diagnosis. Allergic diseases, asthma, and COPD are not risk factors for SARS-CoV-2 infection (Zhang et al., 2020a). The most common comorbidities in our study were hypertension, diabetes mellitus and asthma. Also, bilateral multilobar patchy ground glass opacities, bilateral multilobar patchy ground glass opacities and bilateral alveolar consolidations were the most common radiological findings in present study. Another study showed that of 1099 patients, the median age of the patients was 47 years; $41.9 \%$ of the patients were female. The common symptoms were fever and cough. Ground-glass opacity was the most common radiologic finding on chest $\mathrm{CT}(56.4 \%) .83 .2 \%$ of the patients had lymphocytopenia. Patients often presented without fever, and many did not have abnormal radiologic findings(Guan et al., 2020). Ground-glass opacity in present study was higher common finding. Similar to our study, lymphocytopenia in COVID-19 patients was seen in the other studies(Surveillances, 2020, Diao et al., 2020).In a metha analysis, for 656 patients, fever $88.7 \%$, cough $57.6 \%$ and dyspnea $45.6 \%$ were the most prevalent manifestations(Rodriguez-Morales et al., 2020).Of the 99 patients with $2019-\mathrm{nCoV}$ pneumonia, The average age of the patients was $55 * 5$ years, including 67 men and 32 women. $83 \%$ of the patients had fever, $82 \%$ cough, $31 \%$ shortness of breath, and $11 \%$ myalgia. According to imaging findings, $75 \%$ patients showed bilateral pneumonia, $14 \%$ patients showed multiple mottling and ground-glass opacity, and 1\% patient had pneumothorax (Chen et al., 2020). Of the 10 cases, the average age was 56.5 years , $60 \%$ of the patients were males, Dry cough was the main symptom, followed by fever and fatigue. Chest computed tomography results were nonspecific, mainly with ground-glass attenuation and/or shadow images (Xia et al., 2020). Fever $72 \%$, and cough $83 \%$ were common symptoms in a study. $33 \%$ of them had an abnormal chest radiograph finding or lung crepitations. Lymphopenia was present in 39\% (Young et al., 2020). A total of 5700 patients were included with median age, 63 years, and $39.7 \%$ female. The most common comorbidities were hypertension $56.6 \%$, and diabetes $33.8 \%$ (Richardson et al., 2020). In a study, The prevalence of asthma in patients with COVID-19 was 0.9\% (Li et al., 2020). During the course of a study 21 COVID-19 positive patients were admitted in, Jaipur, $66.66 \%$ of the patients were men and $80.90 \%$ were less than 60 years of old. Almost $33.33 \%$ patients were asymptomatic and of those who were symptomatic, cough was seen in $85.71 \%$ that followed by myalgia $(64.28 \%)$, fever $(78.57 \%)$, and dyspnea (28.57\%). $14.28 \%$ of the cases had co morbidities in the form of diabetes mellitus, hypertension, hypothyroidism, or coronary artery disease. moreover, $52.38 \%$ of the patients had lymphopenia(Bhandari et al., 2020). These patterns in comorbidities and lymphopenia were seen in our study, too.

\section{Other studies in HRCT findings}

is an important component in the diagnostic procedure for patients with suspected COVID-19 infection. Chest CT has limited sensitivity and negative predictive value early after symptom onset, and has little weakness in diagnosis of COVID-19 combined to personal history, clinical symptoms, and initial laboratory findings, and may therefore serve as a standard method for diagnosis of COVID-19 based on its features and transformation rule, the limited number of RT- kits in some centers before initial RT- screening (Bernheim et al., 2020, Chen et al., 2020). Although $12 \%$ of patients were without abnormal lung changes on initial CT images in present study. 
In a study, the most HRCT findings were bilateral parenchymal ground-glass opacities, without or with consolidation in the lung periphery. Especially, $75 \%$ patients with chest HRCT findings related to COVID19 pneumonia had negative results of concurrent nucleic acid tests (He et al., 2020). Then, $21.70 \%$ of positive chest HRCT patients in present study had normal CRP. According to imaging examination in a study, $75 \%$ patients showed bilateral pneumonia, $14 \%$ patients showed multiple mottling and ground-glass opacity, and $1 \%$ patient had pneumothorax (Chen et al., 2020).

In a study, The CRP, ESR, and LDH presented significantly positive correlation with the pneumonia severity on CT. The highest temperature and the severity of opacifications assessed on initial CT were significantly related to the progression of opacifications on follow-up CT(Xiong et al., 2020). In present study, LDH had significantly positive correlation with HRCT. In a study, GGO was the most common manifestation of COVID-19 pneumonia, which could be followed by consolidation and fibrosis. Total CT score, GGO score and fibrosis score of male patients were significantly higher than female in the second week. Male patients had higher consolidation score and fibrosis score than female in the third week. Total CT score and GGO score had weak to moderate correlation with arterial blood gas indices (Shang et al., 2020). In our study, $42.30 \%$ of women and $57.70 \%$ of men had positive HRCT for COVID- a meta-analysis, 40 studies with 4183 COVID-19 patients, the rate of positive CT scan in COVID-19 patients was 94.5\%. Bilateral lung involvement, GGO pulse consolidation or reticular, consolidation, reticular, presence of nodule findings and GGO, in CT scan of COVID-19 pneumonia patients were respectively estimated to be $64.9 \%, 49.2 \%, 30.3 \%$ $, 17.0 \%, 16.6 \%, 94.5 \%$. The lung lesions distribution in patients with COVID-19 was $70.0 \%$ peripheral, $3.9 \%$ central, and $31.1 \%$ peripheral and central (Karimian and Azami, 2020). In a study, of 1014 patients, 59\% had positive RT- results, and $88 \%$ had positive chest CT scans. The sensitivity of chest CT in suggesting COVID-19 based on positive RT- results was $97 \%$. In patients with negative RT- results, $75 \%$ had positive chest CT findings; $48 \%$ were categorized as highly likely cases, with $33 \%$ as probable cases. $60 \%$ to $93 \%$ of cases had positive CT consistent with COVID-19 prior to the initial positive RT- results (Ai et al., 2020).

A total of 14 articles including 1115 patients, pure GGO 69\%, consolidation 47\% and "air bronchogram sign" $46 \%$ were more common than the atypical lesion of "crazy-paving pattern" $15 \%$. while $67 \%$ of patients showed a predominant peripheral distribution (Wan et al., 2020). In a study, included $52 \%$ men, and the mean age was $49 * 5$ years. The major pattern of abnormality observed was bilateral $79 \%$, peripheral $54 \%$, and GGO 65\%. A weak relevance was between the fibrosis score and the value of $\mathrm{PaO} 2$ and $\mathrm{SpO} 2$ (Dai et al., 2020). There was a statistically significant association between level of O2 saturation and HRCT results in present study. In a study, with median age of $45,98 \%$ patients had evidence of abnormal CT compatible with viral pneumonia at baseline (Fang et al., 2020).

It suggested the critical importance to combine the two methods in the early stage of the disease to exclude the SARS-CoV-2 infection. These CT performances of COVID-19 were similar to previous studies. The O2 saturation decreased in patients, which were in consistence with the alteration of indices in patients with lung involvement. the bilateral GGO was higher in the present study. Our results support the use of chest CT for screening for -19 for patients with clinical and laboratory features compatible with COVID-19 infection(Shi et al., 2020). Additionally, a positive relevance was found between the HRCT score, O2 saturation, that was, a patient with higher $\mathrm{CT}$ score tended to have lower O2 saturation.

\section{Limitation}

There were several limitations in this study. First, none of the patients underwent a lung biopsy or autopsy, because of the comparatively better outcomes of the patients in this study. Therefore, the HRCT findings of the lung could not be verified by histopathology. Finally, this was a study with initial HRCT images during hospitalization, mainly demonstrated the early pulmonary lesions in patients with COVID- further longitudinal research was needed to focus on the long-term follow-up, to provide dynamic HRCT evaluation for pulmonary lesions and to obtain the data of long-term pulmonary function changes.

\section{Conclusion}

In the present study, middle-aged, male gender and elderly patients, and patients with comorbidity were 
more susceptible to the COVID-19 infection. W.B.C count, O2 saturation, and ALP were related to lung involvement significantly. Cough, fever, and dyspnea were main symptoms(Zarghami et al., 2020). Abnormal HRCT was a main indicator to evaluate the COVID-19 disease. As a whole, clinical feature, blood laboratory findings, O2 saturation and HRCT findings are critical factors in prognosis of COVID-19 infection.

\section{Disclosure statement}

No potential conflict of interest was reported by the author(s).

\section{Ethical approval}

The current study was reviewed and approved by the Research Ethical Committee, XXXX (IR.XXXX.REC.1399.102) .

\section{Data availability statement}

The data that support the findings of this study are available from the corresponding author upon reasonable request.

\section{References}

AI, T., YANG, Z., HOU, H., ZHAN, C., CHEN, C., LV, W., TAO, Q., SUN, Z. \& XIA, L. 2020. Correlation of chest CT and RT-PCR testing in coronavirus disease 2019 (COVID-19) in China: a report of 1014 cases.Radiology , 200642.

BERNHEIM, A., MEI, X., HUANG, M., YANG, Y., FAYAD, Z. A., ZHANG, N., DIAO, K., LIN, B., ZHU, X. \& LI, K. 2020. Chest CT findings in coronavirus disease-19 (COVID-19): relationship to duration of infection. Radiology, 200463.

BHANDARI, S., BHARGAVA, A., SHARMA, S., KESHWANI, P., SHARMA, R. \& BANERJEE, S. 2020. Clinical profile of covid--19 infected patients admitted in a tertiary care hospital in north India. Journal of The Association of Physicians of India, 68, 13.

CHEN, N., ZHOU, M., DONG, X., QU, J., GONG, F., HAN, Y., QIU, Y., WANG, J., LIU, Y. \& WEI, Y. 2020. Epidemiological and clinical characteristics of 99 cases of 2019 novel coronavirus pneumonia in Wuhan, China: a descriptive study. The Lancet, 395,507-513.

CHUNG, M., BERNHEIM, A., MEI, X., ZHANG, N., HUANG, M., ZENG, X., CUI, J., XU, W., YANG, Y. \& FAYAD, Z. A. 2020. CT imaging features of 2019 novel coronavirus (2019-nCoV). Radiology, 295, 202-207.

DAI, H., ZHANG, X., XIA, J., ZHANG, T., SHANG, Y., HUANG, R., LIU, R., WANG, D., LI, M. \& WU, J. 2020. High-resolution chest CT features and clinical characteristics of patients infected with Covid-19 in Jiangsu, China. International Journal of Infectious Diseases .

DIAO, K., HAN, P., PANG, T., LI, Y. \& YANG, Z. 2020. HRCT imaging features in representative imported cases of 2019 novel coronavirus pneumonia. Precision Clinical Medicine, 3, 9-13.

FANG, Y., ZHANG, H., XIE, J., LIN, M., YING, L., PANG, P. \& JI, W. 2020. Sensitivity of chest CT for COVID-19: comparison to RT-PCR.Radiology , 200432.

GUAN, W.-J., NI, Z.-Y., HU, Y., LIANG, W.-H., OU, C.-Q., HE, J.-X., LIU, L., SHAN, H., LEI, C.-L. \& HUI, D. S. 2020. Clinical characteristics of coronavirus disease 2019 in China. New England journal of medicine, 382, 1708-1720.

HE, X., ZHENG, J., REN, J., ZHENG, G. \& LIU, L. 2020. Chest high-resolution computed tomography imaging findings of coronavirus disease 2019 (Covid-19) pneumonia. International Journal of Radiation Research, 18, 343-349. 
HUANG, C., WANG, Y., LI, X., REN, L., ZHAO, J., HU, Y., ZHANG, L., FAN, G., XU, J. \& GU, X. 2020. Clinical features of patients infected with 2019 novel coronavirus in Wuhan, China. The lancet, 395,497-506.

JIANG, F., DENG, L., ZHANG, L., CAI, Y., CHEUNG, C. W. \& XIA, Z. 2020. Review of the Clinical Characteristics of Coronavirus Disease 2019 (COVID-19). Journal of General Internal Medicine, 35,15451549 .

KANNE, J. P. 2020. Chest CT findings in 2019 novel coronavirus (2019-nCoV) infections from Wuhan, China: key points for the radiologist. Radiological Society of North America.

KARIMIAN, M. \& AZAMI, M. 2020. Computed Tomography Scan Findings in Patients with COVID-19: A Systematic Review and Meta-Analysis.Available at SSRN 3571539 .

LI, X., XU, S., YU, M., WANG, K., TAO, Y., ZHOU, Y., SHI, J., ZHOU, M., WU, B., YANG, Z., ZHANG, C., YUE, J., ZHANG, Z., RENZ, H., LIU, X., XIE, J., XIE, M. \& ZHAO, J. 2020. Risk factors for severity and mortality in adult COVID-19 inpatients in Wuhan. Journal of Allergy and Clinical Immunology .

NG, M.-Y., LEE, E. Y., YANG, J., YANG, F., LI, X., WANG, H., LUI, M. M.-S., LO, C. S.-Y., LEUNG, B. \& KHONG, P.-L. 2020. Imaging profile of the COVID-19 infection: radiologic findings and literature review.Radiology: Cardiothoracic Imaging, 2, e200034.

PAN, F., YE, T., SUN, P., GUI, S., LIANG, B., LI, L., ZHENG, D., WANG, J., HESKETH, R. L. \& YANG, L. 2020. Time course of lung changes on chest CT during recovery from 2019 novel coronavirus (COVID-19) pneumonia. Radiology, 200370.

RICHARDSON, S., HIRSCH, J. S., NARASIMHAN, M., CRAWFORD, J. M., MCGINN, T., DAVIDSON, K. W., BARNABY, D. P., BECKER, L. B., CHELICO, J. D. \& COHEN, S. L. 2020. Presenting characteristics, comorbidities, and outcomes among 5700 patients hospitalized with COVID-19 in the New York City area. Jama .

RODRIGUEZ-MORALES, A. J., CARDONA-OSPINA, J. A., GUTIERREZ-OCAMPO, E., VILLAMIZARPENA, R., HOLGUIN-RIVERA, Y., ESCALERA-ANTEZANA, J. P., ALVARADO-ARNEZ, L. E., BONILLA-ALDANA, D. K., FRANCO-PAREDES, C. \& HENAO-MARTINEZ, A. F. 2020. Clinical, laboratory and imaging features of COVID-19: A systematic review and meta-analysis. Travel medicine and infectious disease, 101623.

SCHURZ, H., SAlie, M., TROMP, G., HOAL, E. G., KinneAR, C. J. \& MOLleR, M. 2019. The X chromosome and sex-specific effects in infectious disease susceptibility. Human Genomics, 13, 2.

SHANG, Y., XU, C., JIANG, F., HUANG, R., LI, Y., ZHOU, Y., XU, F. \& DAI, H. 2020. Clinical characteristics and changes of chest $\mathrm{CT}$ features in 307 patients with common COVID-19 pneumonia infected SARS-CoV-2: A multicenter study in Jiangsu, China. International Journal of Infectious Diseases .

SHI, H., HAN, X., JIANG, N., CAO, Y., ALWALID, O., GU, J., FAN, Y. \& ZHENG, C. 2020. Radiological findings from 81 patients with COVID-19 pneumonia in Wuhan, China: a descriptive study. The Lancet Infectious Diseases .

SOHRABI, C., AlSAFi, Z., O'NeIll, N., KHAN, M., KERWAN, A., AL-JABIR, A., IOSIFIDIS, C. \& AGHA, R. 2020. World Health Organization declares global emergency: A review of the 2019 novel coronavirus (COVID-19).International Journal of Surgery .

SUN, P., QIE, S., LIU, Z., REN, J. \& XI, J. J. 2020. Clinical characteristics of 50466 patients with 2019-nCoV infection.medRxiv .

SURVEILLANCES, V. 2020. The epidemiological characteristics of an outbreak of 2019 novel coronavirus diseases (COVID-19) - China, 2020. China CDC Weekly, 2, 113-122.

TIAN, S., HU, N., LOU, J., CHEN, K., KANG, X., XIANG, Z., CHEN, H., WANG, D., LIU, N. \& LIU, D. 2020. Characteristics of COVID-19 infection in Beijing. Journal of Infection . 
WAN, S., LI, M., YE, Z., YANG, C., CAI, Q., DUAN, S. \& SONG, B. 2020. CT manifestations and clinical characteristics of 1115 patients with coronavirus disease 2019 (COVID-19): A systematic review and meta-analysis. Academic Radiology .

WANG, D., HU, B., HU, C., ZHU, F., LIU, X., ZHANG, J., WANG, B., XIANG, H., CHENG, Z. \& XIONG, Y. 2020. Clinical characteristics of 138 hospitalized patients with 2019 novel coronavirus-infected pneumonia in Wuhan, China. Jama, 323, 1061-1069.

WONG, H. Y. F., LAM, H. Y. S., FONG, A. H.-T., LEUNG, S. T., CHIN, T. W.-Y., LO, C. S. Y., LUI, M. M.-S., LEE, J. C. Y., CHIU, K. W.-H. \& CHUNG, T. 2020. Frequency and distribution of chest radiographic findings in COVID-19 positive patients. Radiology ,201160.

WRAPP, D. Gender-specific Coronavirus-infections in the light of evolution.

WU, Z. \& MCGOOGAN, J. M. 2020. Characteristics of and Important Lessons From the Coronavirus Disease 2019 (COVID-19) Outbreak in China: Summary of a Report of 72314 Cases From the Chinese Center for Disease Control and Prevention. JAMA, 323, 1239-1242.

XIA, X.-Y., WU, J., LIU, H.-L., XIA, H., JIA, B. \& HUANG, W.-X. 2020. Epidemiological and initial clinical characteristics of patients with family aggregation of COVID-19. Journal of Clinical Virology, 104360 .

XIONG, Y., SUN, D., LIU, Y., FAN, Y., ZHAO, L., LI, X. \& ZHU, W. 2020. Clinical and high-resolution CT features of the COVID-19 infection: comparison of the initial and follow-up changes. Investigative radiology

YANG, W., SIRAJUDDIN, A., ZHANG, X., LIU, G., TENG, Z., ZHAO, S. \& LU, M. 2020a. The role of imaging in 2019 novel coronavirus pneumonia (COVID-19). European Radiology, 1-9.

YANG, X., YU, Y., XU, J., SHU, H., LIU, H., WU, Y., ZHANG, L., YU, Z., FANG, M. \& YU, T. 2020b. Clinical course and outcomes of critically ill patients with SARS-CoV-2 pneumonia in Wuhan, China: a single-centered, retrospective, observational study. The Lancet Respiratory Medicine .

YOUNG, B. E., ONG, S. W. X., KALIMUDDIN, S., LOW, J. G., TAN, S. Y., LOH, J., NG, O.-T., MARIMUTHU, K., ANG, L. W. \& MAK, T. M. 2020. Epidemiologic features and clinical course of patients infected with SARS-CoV-2 in Singapore. Jama, 323, 1488-1494.

ZARGHAMI, M., TAGHIZADEH, F., MOOSAZADEH, M., KHERADMAND, M. \& HEYDARI, K. 2020. Validity of self-reporting depression in the Tabari cohort study population. Neuropsychopharmacology Reports, 40,1.

ZARGHAMI, M., TAGHIZADEH, F., SHARIFPOUR, A. \& ALIPOUR, A. 2019. Efficacy of guided selfchange for smoking cessation in chronic obstructive pulmonary disease patients: A randomized controlled clinical trial. Tobacco Induced Diseases, 17.

ZHANG, J.-J., DONG, X., CAO, Y.-Y., YUAN, Y.-D., YANG, Y.-B., YAN, Y.-Q., AKDIS, C. A. \& GAO, Y.-D. 2020a. Clinical characteristics of 140 patients infected with SARS-CoV-2 in Wuhan, China. Allergy .

ZHANG, R., WANG, Z., CHEN, X., CHEN, P., DJAKPO, D. \& LIN, Y. 2020b. Clinical characteristics of 208 patients with COVID-19 in a surrounding city of Wuhan, China.

ZHU, N., ZHANG, D., WANG, W., LI, X., YANG, B., SONG, J., ZHAO, X., HUANG, B., SHI, W. \& LU, R. China Novel Coronavirus I, Research T. 2020. A novel coronavirus from patients with pneumonia in China, 2019.N Engl J Med, 382, 727-733.

\section{Hosted file}

Tables.pdf available at https://authorea.com/users/379879/articles/496091-clinicallaboratory-and-chest-computed-tomography-aspects-of-hospitalized-patients-with-covid- 
19-in-northern-iran

\section{Hosted file}

Figures 1-2.pdf available at https://authorea.com/users/379879/articles/496091-clinicallaboratory-and-chest-computed-tomography-aspects-of-hospitalized-patients-with-covid-19in-northern-iran 